\title{
Preventing the Loss, Improving the Properties of the Circulating Material to Seal Fractures and a Depleted Section of the Well
}

\author{
Hongtao Zhou*, Urinov Abrorbek Axrorovich, Liu Wei \\ Key Laboratory of Unconventional Oil \& Gas Development (China University of Petroleum (East China)) Ministry of Education, Qingdao, \\ People Republic of China
}

Email address:

abrormagnat@mail.ru(U. A. Axrorovich),zhouht@upc.edu.cn(Hongtao Zhou)

${ }^{*}$ Corresponding author

\section{To cite this article:}

Hongtao Zhou, Urinov Abrorbek Axrorovich, Liu Wei. Preventing the Loss, Improving the Properties of the Circulating Material to Seal Fractures and a Depleted Section of the Well. Petroleum Science and Engineering. Vol. 3, No. 2, 2019, pp. 34-38.

doi: $10.11648 /$ j.pse.20190302.11

Received: July 24, 2019; Accepted: August 16, 2019; Published: August 29, 2019

\begin{abstract}
The loss of circulation is an extremely unhealthy phenomenon for drilling, as the liquid solution leaving in the reservoir often leaves the entire drilled breed in the borehole and, in most cases, all the large particles in the solution itself. The settling masses are compacted and can create around the drill tool dense shell and also cause so-called clamp tool-a phenomenon when to remove the drill pipe poses great difficulties. The methods devise in the current research for loss of circulation or eliminated are a reduction of mud density until its hydrostatic pressure becomes equal to the reservoir and Pumping Mudpack with a high concentration of clogging additives in the absorption zone. In addition, the clogging materials to combat the loss of circulation can be used as additives in circulating drilling mud in the drilling of sediment prone to absorption. For the control of absorption, it is possible to use saw dust, flaky and granulated materials or a mixture of all three [1-6]. The flaky materials include cellophane, mica, the husk of sunflower seeds cotton, nut shells. The granulated materials include grinding rubber or asbestos, asphalt. This method differs from other methods in that in order to prevent the loss of the drilling solution to the composition of the chemical compound can be improved by increasing the agent's viscosity in cracks or pores clogging. A series of experiments was conducted to determine the optimal viscosity of the agent, consisting of urea formaldehyde with ammonium sulfate and bentonite. Ammonium sulfate is added to urea formaldehyde in the ratio of $1 / 5$. In a series of experiments, the ratio of chemicals was increased properly. Measurement of solution viscosity was performed by rheometer up to 500MPa. Since there are errors in Rheometer after 500MPA, the measurement of viscosity began by hand with the help of $200 \mathrm{ml}$ of the test tube, weights and steel ball. The obtained results satisfied the requirement for the loss of the chemical of drilling mud. Thus, on the basis of the experiments, it was found that to prevent the loss of the drilling solution to improve the composition of the chemical compound by increasing the viscosity of the agent. This will save the amount of mud and expensive additives save time for drilling and prevent clogging of potentially productive drilling areas.
\end{abstract}

Keywords: Urea Formaldehyde, Sand Pack, Lost Circulation Material, Depleted Zones, Fracture Sealing

\section{Introduction}

As conventional reservoirs have been depleted, the oil industry starts seeking deeper environments that are more challenging. These environments are associated with loss of circulation (LC) which costs the industry nearly a billion dollars a year [7]. The loss mechanisms differ for each candidate formation. On one hand, drilling fluid losses into natural fractures, cavernous, vugular, and high permeability formation are triggered as soon as the drilling fluid pressure exceeds the pore pressure. On the other hand, losses into induced fractures are initiated when the drilling fluid pressure exceeds the fracture pressure [6-8]. Designing a cost-effective drilling fluid is, without a doubt, of primal importance. Investment in drilling fluids can sometimes be very significant, especially when partial or complete fluid losses are encountered while drilling. Drilling 
through cavernous and highly fractured, naturally and sometimes induced, formations could be challenging if the lost circulation material is not properly designed. Lost circulation materials can be classified as fibers, flakes, granular material, or a mixture of all three. [9-14] The materials are needed to stop fluid losses in order to drill ahead. These materials, which come in different forms and have different chemistries, should provide the proper seal to problematic thief zones. The materials ought to block openings within the matrix itself and provide bridging capability between the different fluid flow channels that could exist outside the matrix in open cracks and caverns. $[5,8,15]$ Most of the lost circulation materials tested by the local oil company and the industry have limited capability of blocking pore-throat openings (in the case of clastics) and open cracks and fractures (in the case of carbonates). A lost circulation material that is placed in the wellbore should be timed to react, block fractures, and bridge to provide a perfect seal. The seal could be temporary or even permanent. Permanent seals are often pumped to block thief zones in non-producing formations.
The temporary seals are placed in hydrocarbon-bearing zones that have been encountered while drilling. In the oil industry, most of the conventional LCMs have been tested with different degrees of success. Lost circulation materials in the form of fibers, flakes, granular material and a mixture of all three have proved to be effective in some instances. The tendency, however, has moved towards using polymeric materials.

LC is defined as losing some drilling mud into the formation, thief zone, and classified based on the LC severity, barrels per hour, as 1) seepage $(<10 \mathrm{bbl} / \mathrm{hr}), 2)$ partial $(10-50 \mathrm{bbl} / \mathrm{hr}), 3)$ severe $(>90 \mathrm{bbl} / \mathrm{hr}), 4)$ total losses (no returns). However, this classification does not explain the mechanisms at which losses occur; resulting in appropriate treatments. [3, 9, 16-22] By identifying the loss severity, proper remedial action takes place to mitigate or stop the losses. Seepage and partial losses are often cured using conventional lost circulation materials; however, when it comes to severe or total losses, special treatments are used.

Table 1. Lost cicualtion

\begin{tabular}{llll}
\hline Seepage Losses & Partial Losses & Severe Losses & Total Losses \\
\hline$<10 \mathrm{bbl} / \mathrm{hr}$ & $>50 \mathrm{bbl} / \mathrm{hr}$ & $>90 \mathrm{bbl} / \mathrm{hr}$ & No returns \\
$\begin{array}{l}\text { Porous and permeable sand, gravel, } \\
\text { shell beds }\end{array}$ & Small open fractures & $\begin{array}{l}\text { A large section of unconsolidated } \\
\text { sands or fractures }\end{array}$ & Cavernous/large fractures \\
\hline
\end{tabular}

In addition, the rate of loss in a producing zone is of greater concern than the small loss in a non-productive zone because formation damage can reduce overall productivity and recovery.

\section{Methodology}

There are two methods of LCM experiment:

Experimental chemical reagents, including ammonium sulfate, urea formaldehyde, and bentonite, have been shown to be highly effective.

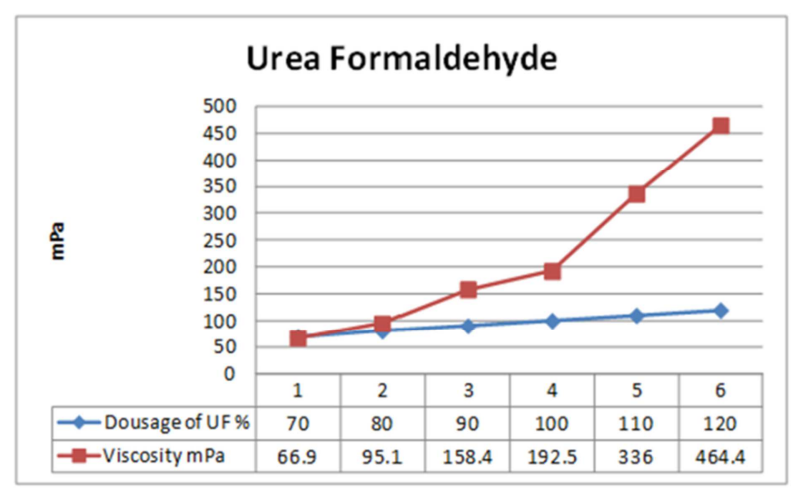

Figure 1. Amount of Urea formaldehyde in water.
LCM's performance evaluation is a crucial step that involves different factors that contributes to the overall sealing efficiency. The sealing efficiency of LCM's is defined here as the maximum pressure at which the formed seal breaks and fluid starts to flow again through the slotted area. Two specifically developed apparatuses were used to optimize the combination of LCMs combination and investigate their ability to sealing wide fractures at different pressures. In this experiment used, effective LCM formulations with proper concentration and sandpack, to seal pores and depleted zones. The formulation consists of urea formaldehyde resin, ammonium sulfate, and bentonite according to the previously published literature [16]. Other testing equipment has been developed to evaluate the sealing efficiency of LCM treatments in sealing permeable/impermeable depleted/fractured formations. [6, 14, 20-22] Both sand pack and total LCM concentration were found to have a significant effect on the sealing efficiency. It was also concluded that the fluid loss volume is not a good parameter to measure the sealing efficiency of LCM treatments. The permeability is determined from the Darcy law as per defined in published literature [11]. The sand pack is used to perform the action the procedure is described below.

Table 2. Urea formaldehyde.

\begin{tabular}{lllllll}
\hline Number of experiments & $\mathbf{1}$ & $\mathbf{2}$ & $\mathbf{3}$ & $\mathbf{4}$ & $\mathbf{5}$ \\
\hline Urea Formaldehyde in $\%$ & 70 & 80 & 90 & 100 & 110 \\
Viscosity $\mathrm{MPa}$ & 66,9 & 95,1 & 158,4 & 120 & 192,5 & 336 \\
\hline
\end{tabular}

Step 1 The pure weight of the sand pack was measured after sand preparation starting from washing and drying in the oven for 20 hours.

Step 2 The dried sand is fixed in the tube and other parts of 
the device are tightened and water is injected for 3-4 hours. The water flow at the rate of $2 \mathrm{ml} / \mathrm{min}$. At the end of the appliance, the container is put for water draining, and $200 \mathrm{ml}$ of water should be removed at the time of LCM saturating. In the second phase it is fixed again for LCM with a flow rate of $2 \mathrm{ml} / \mathrm{min}$ injection. After $200 \mathrm{ml}$ of water is removed, the LCM will be completely covered and the water will be turned on for 2 times. When the water was started 2 times, we were sure that the water did not flow from the other side of the unit. The pressure of the pump was $15 \mathrm{MPa}$. Then the expected result was achieved.

The experience of the device is equipped with 4-part pressure gauges i.e. $\mathrm{P}_{1}, \mathrm{P}_{2}, \mathrm{P}_{3}$, and $\mathrm{P}_{4}$. These gauges are mounted on the pipe as an array. The pressure difference shows how the experiment progresses and how much the chemical fluid is spreading and how much the pores are covered. When the fluid was injected into the pipe, the input pressure was $18.6 \mathrm{MPa}$. $\mathrm{P}_{1}$ showed $2.09 \mathrm{MPa}$. The flow rate of $2 \mathrm{ml} / \mathrm{min}$. $\mathrm{P}_{2} 0.04 \mathrm{P}_{3}$ was $0.03 \mathrm{MPa}$ and $\mathrm{P}_{4}$ was $0.01 \mathrm{MPa}$. An hour and thirty minutes after $\mathrm{P}_{1}=3.10 ; \mathrm{P}_{2}=2.05 ; \mathrm{P}_{3}=0.93$ and $\mathrm{P}_{4}=0.63$. The results after 50 minutes are $\mathrm{P}_{1}=3.9 ; \mathrm{P}_{2}=2.05$; $\mathrm{P}_{3}=1.04$ and $\mathrm{P}_{4}=0.98 \mathrm{MPa}$. Final results: After 40 minutes, $\mathrm{P}_{1}=6.60 ; \mathrm{P}_{2}=3.06 ; \mathrm{P}_{3}=1.86 ;$ and $\mathrm{P}_{4}=0.95 \mathrm{MPa}$. The input pressure on this device was $29.8 \mathrm{MPa}$.

\section{Result}

The study was conducted, as per the test procedure and methodology discussed earlier, to qualitatively determine the effect of the selected LCM. The results are presented below in Table 1.

Table 3. Sand Pack apparatus data.

\begin{tabular}{|c|c|c|c|c|c|c|c|c|}
\hline № & $\mathbf{P}_{\text {entrance }}$ & Time & $\mathbf{P}_{1}$ & $\mathbf{P}_{2}$ & $\mathbf{P}_{3}$ & $\mathbf{P}_{4}$ & Temperature & Flow rate \\
\hline 1 & 18,6 & $15: 00$ & 2,09 & 0,04 & 0,03 & 0,01 & $106 * \mathrm{C}$ & $2 \mathrm{ml}$ \\
\hline 2 & 18,7 & $16: 30$ & 3,1 & 2,05 & 0,93 & 0,63 & $108 * \mathrm{C}$ & $2 \mathrm{ml}$ \\
\hline 3 & 19,01 & $17: 20$ & 3,9 & 2,35 & 1,04 & 0,98 & $110 * \mathrm{C}$ & $2 \mathrm{ml}$ \\
\hline
\end{tabular}

In table $1, P_{\text {initial }}$ represents the initial volume at which the first seal was developed while $P_{\max }$ represent the highest sealing pressure recorded. To evaluate LCM, each individual test for sand pack prepared several times. From table 2 to table 5 shows the data about rheometr the mixture of Urea Formaldehyde and ammonium sulfate.

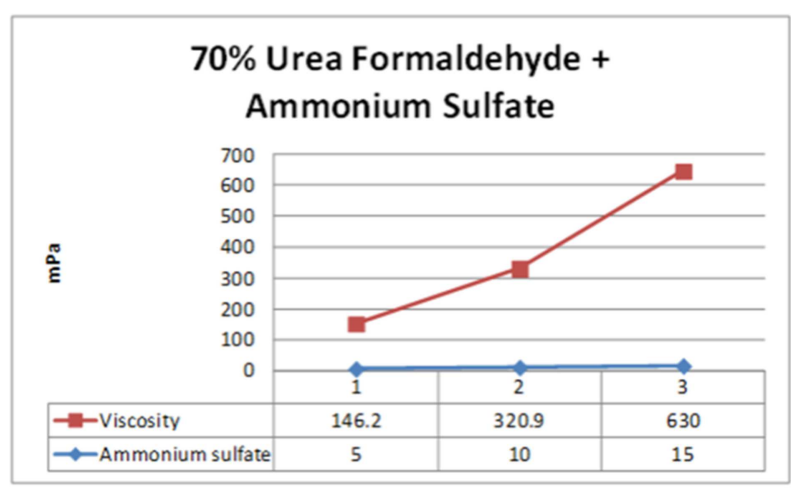

Figure 2. 70\% Urea formaldehyde and ammonium sulfate (5\%-15\%).

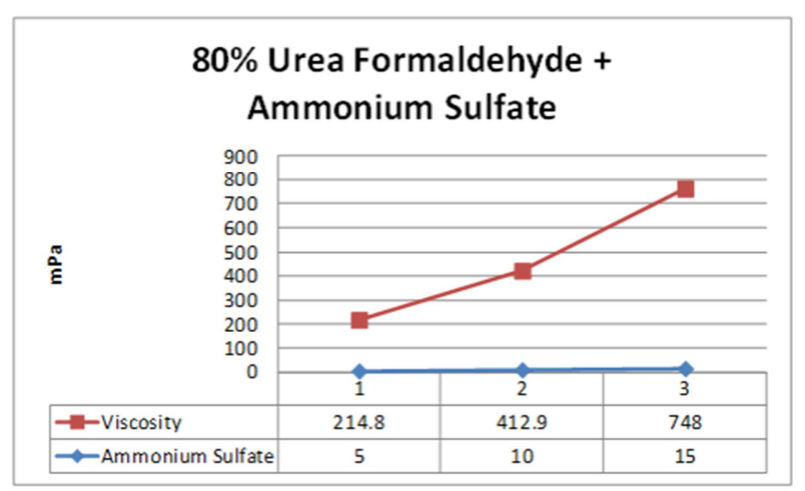

Figure 3. $80 \%$ Urea formaldehyde and ammonium sulfate (5\%-15\%).
Table 4. 70\% Urea Formaldehyde.

\begin{tabular}{llll}
\hline Number of experiments & $\mathbf{1}$ & $\mathbf{2}$ & $\mathbf{3}$ \\
\hline Ammonium sulfate & 6 & 10 & 15 \\
Viscosity $\mathrm{MPa}$ & 146,2 & 320,9 & 630 \\
\hline
\end{tabular}

Table 5. $80 \%$ Urea Formaldehyde.

\begin{tabular}{llll}
\hline Number of experiments & $\mathbf{1}$ & $\mathbf{2}$ & $\mathbf{3}$ \\
\hline Ammonium sulfate & 5 & 10 & 15 \\
Viscosity MPa & 214,8 & 412,9 & 748 \\
\hline
\end{tabular}

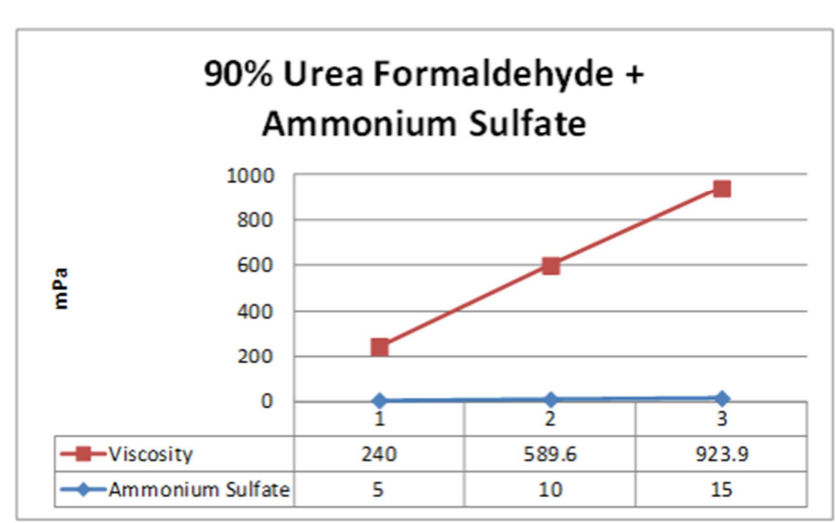

Figure 4. 90\% Urea formaldehyde and ammonium sulfate (5\%-15\%).

Table 6. $90 \%$ Urea Formaldehyde.

\begin{tabular}{llll}
\hline Number of experiments & $\mathbf{1}$ & $\mathbf{2}$ & $\mathbf{3}$ \\
\hline Ammonium sulfate & 5 & 10 & 15 \\
Viscosity MPa & 240 & 589,6 & 923,9 \\
\hline
\end{tabular}

\section{Sand Pack Apparatus Results Summary}

Sandpack experiment 
Open the water chamber to check for water, keeps the channel the same turn on the model and flow rate when temperature reaches begin recording the pressure with time and this process will take about 7 to $8 \mathrm{hr}$ and then after finishing it chemical flooding process begins.

Chemical flooding

Follow the same procedure of water flooding.

How to calculate the chemical and time needed for the experiment.

The volume of LCM saturation=300PV.

Injection rate $2 \mathrm{ml} / \mathrm{min}$.

The half volume of LCM saturation will be divided by the flow rate example $150 / 2=75 \mathrm{~min}$.

Water weight M5-M4-M1 (From this formula).

Water volume $(\mathrm{V})=\mathrm{Mw} / \rho=($ the volume of water here will refer as porosity).

And finally second water flooding with a similar procedure for the first water flooding.

\section{Discussion}

A total of 30 tests to evaluate the integrity of the seal formed under elevated pressures were conducted using the Sand Pack. The results are summarized in Table 3. The fluid loss values from the screening tests were included within the table to show how they are comparable with the fluid loss per cycle values. Random tests were repeated to ensure the repeatability of the results. Some fluid loss per cycle values were significantly higher than the LPA values and this is due to the porous seal resulting from high concentration of larger particles.

\section{Conclusion}

Implementing a thorough plan is essential to mitigating lost circulation with non-aqueous fluids. Preventing lost circulation in non-aqueous fluids can be easier than restoring circulation. RGC has proven to be one of the more effective lost circulation mitigation materials in both the field and laboratory. "One-sack" engineered combinations of sized LCM can simplify lost-circulation treatment. Sizing lostcirculation treatments by volume of material is a more realistic approach than using weight, particularly when incorporating materials with a relatively low specific gravity. Chemical systems that form pliable or flexible ultra-high viscosity treatments may be necessary to treat the most severe lost circulation events.

\section{Acknowledgements}

The author expresses his appreciation to journal "Science Publishing Group" for allowing the publication of this paper. Also, the guidance and the extensive expertise of my supervisors Prof. Zhou Hong Tao, Prof. Liu Wei, and my friends Fahad Ali and Muhammad Kashif (China University of Petroleum) are acknowledged. Without their support and insight, this paper would not have been possible.

\section{References}

[1] "Alternative Lost Circulation Material for Depleted Reservoirs | J. Luzardo | Request PDF." [Online]. Available: https://www.researchgate.net/publication/313560600_Alternat ive_Lost_Circulation_Material_for_Depleted_Reservoirs. [Accessed: 14-Aug-2019].

[2] “Lost Circulation Materials - Halliburton." [Online]. Available: https://www.halliburton.com/enUS/ps/baroid/fluid-services/fluid-additives/lost-circulationmaterials/default.html. [Accessed: 14-Aug-2019].

[3] “(PDF) Experimental Study and Modeling of Smart Loss Circulation Materials; Advantages and Promises." [Online]. Available:

https://www.researchgate.net/publication/325217249_Experim ental_Study_and_Modeling_of_Smart_Loss_Circulation_Mat erials_Advantages_and_Promises. [Accessed: 14-Aug-2019].

[4] D. Iwashita, N. Morita, M. Tominaga, and W. University, "Shear-Type Borehole Wall Shifts Induced During Lost Circulations," p. 13, 2008.

[5] H. Wang et al., "Best Practice in Understanding and Managing Lost Circulation Challenges," SPE Drill. Complet, vol. 23, no. 02, pp. 168-175, Jun. 2008.

[6] N. Gupta, M. Suhaimi, de Crevoisier, S. Rouat, S. Commerçon, and P. CongoRep, "NOVEL FIBER-BASED LOST CIRCULATION TREATMENT CURED TOTAL LOSSES IN DEPLETED ZONES IN EMERAUDE FIELD,” p. 9.

[7] G. Alshubbar, R. Nygaard, and M. Jeennakorn, "The effect of wellbore circulation on building an LCM bridge at the fracture aperture,” J. Pet. Sci. Eng., vol. 165, pp. 550-556, Jun. 2018.

[8] D. Whitfill, "Lost Circulation Material Selection, Particle Size Distribution and Fracture Modeling with Fracture Simulation Software," in IADC/SPE Asia Pacific Drilling Technology Conference and Exhibition, Jakarta, Indonesia, 2008.

[9] P. Valsecchi, "On the Shear Degradation of Lost-Circulation Materials,” SPE Drill. Complet., vol. 29, no. 03, pp. 323-328, Sep. 2014.

[10] "lost circulation materials - OnePetro." [Online]. Available: https://onepetro.org/search?q=lost+circulation+materials\&pee $\mathrm{r}$ reviewed $=\&$ published between $=\&$ from year $=\&$ to year $=\& \mathrm{r}$ ows $=25$. [Accessed: 13-May-2019].

[11] "PET524-2b-permeability.pdf."

[12] N. Morita and C. Inc, "Theory of Lost Circulation Pressure," p. 16.

[13] S. Savari, D. L. Whiftill, D. E. Jamison, and A. Kumar, "A Method To Evaluate Lost-Circulation Materials - Investigation of Effective Wellbore-Strengthening Applications," SPE Drill. Complet, vol. 29, no. 03, pp. 329-333, Sep. 2014.

[14] G. C. Howard and P. P. Scott, "An Analysis and the Control of Lost Circulation,” J. Pet. Technol., vol. 3, no. 06, pp. 171-182, Jun. 1951.

[15] C. R. Miranda et al., "Materials for Controlling Severe Lost Circulation - Laboratory Evaluation," in SPE Latin America and Caribbean Petroleum Engineering Conference, Buenos Aires, Argentina, 2017. 
[16] B. Andersen and B. G. Brehmer, "Hardener for use in-ureaformaldehyde and urea-melamine-formaldehyde based adhesives, an adhesive composition comprising said hardener and its use," US6590013B1, 08-Jul-2003.

[17] F. João, M. Ohlmeyer, A. Mendes, C. M. R, L. Carvalho, and F. Magalhães, Evaluation of urea-formaldehyde adhesives performance by recently developed mechanical tests, vol. 31 . 2011.

[18] “Lost Circulation Materials - Halliburton." [Online]. Available: https://www.halliburton.com/enUS/ps/baroid/fluid-services/fluid-additives/lost-circulationmaterials/default.html. [Accessed: 14-Aug-2019].

[19] "(PDF) Effect of different hardeners for urea-formaldehyde resin on properties of birch plywood." [Online]. Available: https://www.researchgate.net/publication/308613314_Effect_o f_different_hardeners_for_ureaformaldehyde_resin_on properties_of_birch_plywood. [Accessed: 13-May-2019].

[20] "Lost Circulation - 1st Edition." [Online]. Available: https://www.elsevier.com/books/lost-circulation/lavrov/978-012-803916-8. [Accessed: 14-Aug-2019].
[21] A. Saasen et al., "Permanent Abandonment of a North Sea Well Using Unconsolidated Well-Plugging Material," SPE Drill. Complet, vol. 26, no. 03, pp. 371-375, Sep. 2011.

[22] A. Mehrabian, D. E. Jamison, and S. G. Teodorescu, "Geomechanics of Lost-Circulation Events and WellboreStrengthening Operations," SPE J., vol. 20, no. 06, pp. 13051316, Dec. 2015.

[23] "Lost Circulation Materials | Innospec Oilfield." [Online]. Available: https://www.innospecoilfield.com/drilling/lostcirculation-materials/. [Accessed: 14-Aug-2019].

[24] "Lost-circulation Materials and their Evaluation - OnePetro." [Online]. Available: https://www.onepetro.org/conferencepaper/API-56-352. [Accessed: 14-Aug-2019].

[25] A. Nasiri, A. Ghaffarkhah, Z. A. Dijvejin, M. Mostofi, and M. K. Moraveji, "Bridging performance of new eco-friendly lost circulation materials," Pet. Explor. Dev., vol. 45, no. 6, pp. 1154-1165, Dec. 2018.

[26] C. Xu, Y. Kang, L. You, S. Li, and F. Chen, "High-Strength, High-Stability Pill System To Prevent Lost Circulation," SPE Drill. Complet, vol. 29, no. 03, pp. 334-343, Sep. 2014. 